\title{
THE ARIDIZATION EFFECT \\ ON THE CHARACTERISTICS OF THE SUBSTRATE AND BIOTOPIC DISTRIBUTION OF FUNGI SPECIES OF THE POLYPORUS S.L. GENUS IN THE SOUTHEAST OF WESTERN SIBERIA
} (C) 2020

Vlasenko Vyacheslav Aleksandrovich, candidate of biological sciences, senior researcher of Lower Plants Laboratory

Vlasenko Anastasiya Vladimirovna, candidate of biological sciences, senior researcher of Lower Plants Laboratory Central Siberian Botanical Garden of Siberian Branch of Russian Academy of Sciences

(Novosibirsk, Russian Federation)

Turmunkh Dejidmaa, PhD, senior researcher of Plant Pathology Laboratory

Plant Protection Research Institute of Mongolia (Ulaanbaatar, Mongolia)

Abstract. The paper deals with the features of substrate and biotopic distribution of fungi species of the Polyporus s.l. genus in the southeast of Western Siberia. Most species have a wide range of substrates represented by various species of woody plants. The most widespread and common species are able to develop a wide range of substrates. Rare species are distinguished by a narrow substrate spectrum. For a rare species $P$. rhizophilus, adapted to exist in the conditions of subarid regions, found only in steppe biome communities, steppe grasses (Stipa, Festuca) are the only substrate. Most species grow on deciduous wood, only some species can grow on conifers, and only the taiga species $P$. tubaeformis develops exclusively on conifers in mountainous regions. Fungi substrates are represented by 11 species of angiosperms, 3 species of gymnosperms and steppe grasses. Most species are common in numerous communities; all of them are characterized by a high frequency of occurrence and colonize a wide range of substrates. Biotopically narrowly specialized species are few in number; they are characterized by narrow substrate specialization. In anthropogenic habitats, 6 species out of 14 growing in natural communities were recorded. On the plain territory, 10 species of the genus Polyporus were identified, while 14 species were found in mountain systems, since mountain humid areas contain the largest spectrum of substrates for fungi. The greatest diversity of Polyporus species is recorded in dark coniferous forests, among which the number of species is dominated by black aspen-fir forests. With an increase in aridization and a change in plant communities, rare relict mountain taiga, nemoral and typical taiga species are eliminated. The smallest number of Polyporus species is found in the steppe communities of subarid regions.

Keywords: fungi; Polyporus; subarid regions; humid regions; polyporoid fungi; environmental structure; ecological diversity; distribution; substrate specificity; habitats; Western Siberia; plain; mountains.

$* * *$

\section{ОПРЕДЕЛЕНИЕ АНТРОПОТЕХНОГЕННОЙ НАГРУЗКИ НА ОБЪЕКТЫ ОКРУЖАЮЩЕЙ СРЕДЫ ПРИХОПЕРЬЯ}

(C) 2020

Громова Татьяна Сергеевна, аспирант кафедры ботаники и экологии

Сираева Ирина Салаватовна, аспирант кафедры ботаники и экологии

Ермоленко Анна Сергеевна, аспирант кафедры ботаники и экологии

Саратовский национальный исследовательский государственный университет имени Н.Г. Чернышевского

(2. Саратов, Российская Федерачия)

Ларионов Николай Викторович, кандидат биологических наук, директор

Котельниковская средняя общеобразовательная школа № 2

(2. Котельники, Московская область, Российская Федерация)

Ларионов Максим Викторович, доктор биологических наук, доцент, профессор кафедры биологии и экологии

Балашовский институт (филиал) Саратовского национального исследовательского государственного университета имени Н.Г. Чернышевского (г. Балашов, Саратовская область, Российская Федераџия)

Аннотация. Выявлены преимущественные источники антропотехногенных воздействий на окружающую среду городских и пригородных территорий Воронежской и Саратовской областей, входящих в субрегион Прихоперья. Среди совокупных урбано-техногенных источников следует выделить активность пешеходов и автомобильного транспорта. Эти условия характеризуют местный фон совокупной антропотехногенной нагрузки применительно к поселениям района исследований. К числу ее основных проявлений относятся уплотненность почв, плотность дорожно-тропиночной сети, захламленность. Средние арифметические значения деградационных воздействий проанализированы для поселений рассматриваемого субрегиона. Разработана шкала балльной экологической оценки состояния окружающей среды, дифференцированная по населенным пунктам Прихоперья. Высокая антропотехногенная нагрузка выявлена в г. Балашов, средняя - в г. Борисоглебск и г. Ртищево, низкая - в г. Поворино и П.г.т. Грибановский, крайне низкая нагрузка - в 
р.п. Романовка, г. Аркадак и г. Новохоперск. Полученные и проанализированные значения антропотехногенных нагрузок на объекты окружающей среды демонстрируют особенности ее состояния и направления ее деградации, уровни экологической комфортности урбанизированных районов для населения. Систему управления качеством окружающей среды, городским и пригородным природопользованием в Прихоперье необходимо переориентировать на экосистемную основу с использованием приведенных и проанализированных в статье эколого-оценочных критериев и результатов экологического мониторинга.

Ключевые слова: объекты окружающей среды; уплотненность почв; плотность дорожно-тропиночной сети; захламленность почв; интенсивность движения пешеходов; интенсивность движения автотранспорта; результаты экологического мониторинга; эколого-оценочные баллы; экологические тренды.

Прихоперье представляет собой обширную территорию, занимающую долинные природно-территориальные комплексы бассейна реки Хопер и прилегающие к ним районы. Гидрографическая сеть, представленная малыми и средними реками, обусловила относительную изрезанность орографического рисунка и неравномерность распределения основных типов и подтипов почв в пределах Окско-Донской равнины и прилегающих участков [1-4]. В Прихоперье очевидны деградационные явления в природных экосистемах и ландшафтах.

Почвенно-геохимические особенности и биогеоценотический рисунок Прихоперья определяются, прежде всего, неравномерным распределением разных вариантов степной, луговой и лесной растительности. Реки, крупные ручьи и пойменные природные комплексы, представленные лесными массивами, лугами, болотами, старичными образованиями [5-8], составляют основу природно-экологических каркасов. В этом контексте разнообразие растительности [9; 10] способствует поддержанию устойчивости и продуктивности местных геокомплексов, а также является условием сложности их организации. Сложность ландшафтной структуры Саратовского и Воронежского Прихоперья [11-13], как и Прихоперского субрегиона в пределах соседней Пензенской области [14], а также неравномерность распределения водотоков, погодно-климатические особенности обусловливают дискретность, мозаичность территориального размещения и функциональной основы биогеоценозов. Разнообразие ландшафтов и экосистем обусловили высокую ресурсную ценность для общества и народного хозяйства, что выразилось в различных направлениях сельского хозяйства, лесохозяйственного, производственного, энергетического и транспортного комплексов в данном субрегионе.

Большое значение для поддержания экологической устойчивости и биологического разнообразия принадлежит экотонным экосистемам, развившимся как в долинных комплексах, водосборных бассейнах, так и на обширных и небольших водоразделах, в том числе на границах отдельных урочищ, подурочищ, фаций в лесостепных, лесных, лугово-степных, луговых, болотных, старично-озерных комплексов. Во многом относительная густота гидрографической сети способствует геоморфологическому, почвенному, микроклиматическому и экосистемному разнообразию территории Прихоперья. Эти природные комплексы концентрируют биологическое и генетическое разнообразие многих организмов, способствуют поддержанию экологического равновесия в экосистемах, примыкающих к экотонным сообществам. Это же относится как к урбанизированным экосистемам, так и к экологическим системам загородных районов.

В настоящее время антропотехногенный фактор в Прихоперье приобрел комплексный и при этом мно- гогранный характер. В наибольшей степени он проявляется в крупных населенных пунктах, прежде всего в поселениях - центрах муниципальных районов $[13 ; 15]$, преимущественно заключающих в себе львиную долю производств, различных вариантов сервиса, сферы обслуживания и иных сфер народного хозяйства. Результаты сельскохозяйственного производства также в значительной мере связаны с реализацией, хранением и переработкой полученного сырья, с дальнейшим продвижением продукции агропромышленного сектора на местные и межрегиональные рынки. Доминирующее значение приобрел автомобильный транспорт, обеспечивающий доминантную роль в ухудшении экологической обстановки. Отрицательные по геохимическим, биогеохимическим и, в числе прочих проявлений, экотоксическим эффектам последствия для окружающей среды заключаются в образовании и распространении широкого наименования газообразных веществ, элементов группы тяжелых металлов, углеводородов различного состава и реакционной способности.

Поступление их в разные среды и загрязнение ими косных, биокосных, биотических компонентов экосистем, в особенности на урбанизированных и пригородных территориях, определенно можно расценивать в качестве первостепенных, реальных факторов экологических рисков локального и районного значения в Прихоперье. Поэтому особенно важно установить значимость основных источников и причин негативных воздействий на окружающую среду рассматриваемого субрегиона. Эта значимость определяется в соответствующих параметрах последствий видов антропотехногенного прессинга на объекты окружающей среды.

Цель работы: обобщение и анализ результатов определения преимущественных видов и мощности антропотехногенных воздействий на окружающую среду в условиях урбаносреды Прихоперья, выявление основных трендов экологической обстановки и обоснование значимости материалов осуществленных эколого-мониторинговых исследований в эколого-охранной деятельности, в деле создания и эффективного использования художественно-декоративных и эколого-защитных зеленых насаждений, а также в работе по обеспечению устойчивого эколого-хозяйственного развития городских и пригородных территорий данного субрегиона.

\section{Методы исследований}

Регистрация и интерпретация уровней замусоренности и уплотнения почв и почвогрунтов осуществлялись на основе общепринятой, стандартизированной методики [16]. Плотность дорожно-тропиночной сети (ДТС) выявлялась по ее составным компонентам, в том числе не относящимся к их планировке (прикатанные газоны, протоптанные тропинки 
Громова Т.С., Сираева И.С., Ермоленко А.С., Ларионов Н.В., Ларионов М.В.

Определение антропотехногенной нагрузки на объекты окружающей среды Прихоперья

Общая биология

вне основных пешеходных дорожек и т.п.), и анализировалась по общей площади этих территориальных образований $[17 ; 18]$. Устанавливалась интенсивность пешеходного [19; 20] и автомобильного движения [20;21] за выбранные единицы времени в удобной для наблюдений и регистрации транспортных средств модификации [22]. Данные мониторинга статистически обработаны, проанализированы. Результаты получены в статистически доверительном интервале 95\%. В статобработке использован сервис Microsoft Office Excel 2019. Полученные средние арифметические значения показателей антропотехногенных воздействий переводились в эколого-оценочные баллы. Градация значений баллов выглядит следующим образом: 7-10 баллов - высокое значение оцениваемого показателя, 4-6 - среднее (умеренное) значение, 1-3 - низкое (незначительное) значение. Итоговый анализ выполнялся по суммам баллов по каждому из экологических показателей, характеризующих соответствующие антропотехногенные воздействия. Градация балльной оценки: 4150 баллов - высокая антропотехногенная нагрузка, 31-40 баллов - средняя нагрузка, 21-30 баллов низкая нагрузка, до 20 баллов - крайне низкая (незначительная) нагрузка. В итоге выявлены и дифференцированы уровни результирующих нагрузок на окружающую среду в поселениях субрегиона исследований.

\section{Результаты исследований}

В данной работе приведены результаты определения в течение многолетнего периода времени (2011-2019 гг.) антропотехногенной нагрузки на объекты окружающей среды в Прихоперье на примере муниципальных районов Воронежской области, Саратовской области. В составе первого региона рассмотрены Грибановский, Поворинский, Новохоперский, Борисоглебский муниципальные районы, в составе второго региона - Аркадакский, Ртищевский, Романовский и Балашовский районы.

Постоянные посещения населенных пунктов Прихоперья, анализ материалов экологических статистических материалов-ежегодников, а самое важное, многолетние наблюдения за качеством окружающей среды позволили установить объекты, испытывающие непосредственный антропогенно-техногенный пресс. Это прежде всего почвенный и растительный покровы, а также атмосферный воздух. Кроме того, наблюдения показали, что приоритетными источниками давления на эти среды являются автомобильный транспорт и сами жители (пешеходы). При этом нагрузка от автомобилепотоков обусловлена в последние годы, в том числе в настоящее время, развитием внутригородского и внешнего наземного транспорта обусловливающего экологически кризисное состояние окружающей среды вблизи транспортных и инженерно-коммуникационных зон. Это также объясняется территориально-планировочным, связующим и хозяйственным значением автомобильных сообщений между функциональными зонами и объектами внутри них, поселениями и их окрестными территориями, между центрами административных районов и, что особенно важно, между разными регионами.

Автомобильный транспорт в районе исследований призван в первую очередь обслуживать различные техносферные (энергетики, торговли, сферы услуг, производства, стройплощадок, топливозаправочные станции, коммунальные и многие другие), социальные и культурные объекты. Помимо производственно-хозяйственных и общественных функций автотранспорт осуществляет обеспечение частных потребностей населения. Поэтому автотранспортная активность представляет интегрированный, комплексный фактор техногенных воздействий на окружающую среду и на ее объекты.

Как свидетельствуют наблюдения и экомониторинговые исследования, автотранспортная и пешеходная нагрузка обусловливают основной фон антропогенных нарушений в биокосных, биотических и косных элементах экосистем в Прихоперье. Статистически обработанные результаты сведены в таблице 1.

Уплотненность почв наивысшая установлена в городах с максимально выраженным транспортно-хо-

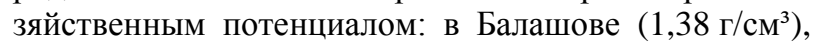

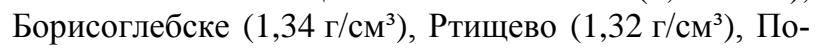

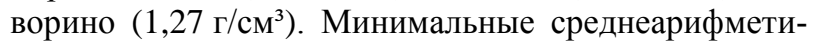
ческие значения этого антропогенно-деградационного фактора характерны для поселений с незначительным транспортно-хозяйственным потенциалом в сравнении с вышеназванными населенными пунктами - для рабочего поселка Романовка $\left(1,07\right.$ г/ $\left.\mathrm{cm}^{3}\right)$, горо-

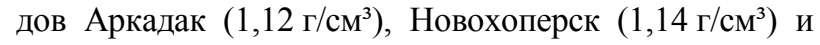

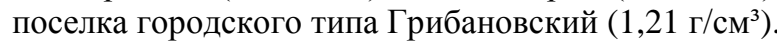

Показатели ДТС распределены аналогичным значениям уплотненности почв образом. Максимальные усредненные значения ДТС выражены в Балашове (43,2\%), Борисоглебске (39,5\%), Ртищево (35,3\%), Поворино (32,3\%). Анализ результатов определения интенсивности пешеходного и автомобильного движений выявил схожую тенденцию усиления этих деградационных условий в наиболее крупных поселениях с наибольшим совокупным транспортным и хозяйственным потенциалом. Изменение значений интенсивности передвижения пешеходов и автомобилепотоков в рассматриваемых поселениях установлено в аналогичном порядке.

Таблица 1 - Среднестатистические значения параметров антропотехногенной деградации объектов окружающей среды Прихоперья

\begin{tabular}{|l|c|c|c|c|c|c|c|c|}
\hline Насел. пункты & $\begin{array}{c}\text { Гриба- } \\
\text { новский }\end{array}$ & $\begin{array}{c}\text { Пово- } \\
\text { рино }\end{array}$ & $\begin{array}{c}\text { Ново- } \\
\text { хоперск }\end{array}$ & $\begin{array}{c}\text { Борисо- } \\
\text { глебск }\end{array}$ & $\begin{array}{c}\text { Арка- } \\
\text { дак }\end{array}$ & $\begin{array}{c}\text { Рти- } \\
\text { щево }\end{array}$ & $\begin{array}{c}\text { Рома- } \\
\text { новка }\end{array}$ \\
Бала- \\
шов
\end{tabular}


Громова Т.С., Сираева И.С., Ермоленко А.С., Ларионов Н.В., Ларионов М.В.

При анализе параметров захламленности, являющихся, по существу, общесанитарными показателями состояния почвенного и растительного покровов и влияющих, в том числе, на показатели локального загрязнения приземного воздуха, выявлены некоторые особенности. Максимум захламленности приходится на Грибановский $(25,5 \%)$ и Поворино $(22,8 \%)$. В среднем, наименьшая замусоренность выявлена в Борисоглебске (8,6\%), Романовке $(10,3 \%)$, Аркадаке $(11,4 \%)$, Новохоперске $(12,4 \%)$. Такие различия в значениях связаны с соответствующим общим уровнем и периодичностью ухода за городскими и пригородными территориями. Относительно своевременная уборка населенных территорий, главным образом, в Борисоглебске, Романовке, Аркадаке, Новохоперске обеспечивает снижение токсического влияния компонентов мусора на объекты окружающей среды. Захламление представляет собой дополнительный фактор эколого-токсической и эколого-эпидемической опасности для домашних животных и (прямо и опосредованно по трофическим цепям в антропоэкосистемах) для населения и гостей данных урбанизированных районов.

Несмотря на установленные критериальные значения описываемых эколого-оценочных показателей, они не дают в полной мере возможность охарактеризовать различия в установленных среднеарифметических параметрах между поселениями. Кроме этого, затруднен и их интегрированный анализ. Поэтому для раскрытия всей полноты картины совокупного деградационного влияния общества на окружающую среду урбанизированных территорий района исследований выполнен комплексный анализ полученных среднеарифметических результатов экологического мониторинга в баллах.

Эколого-оценочные баллы дифференцированно раскрывают значимость каждого рассматриваемого антропогенно-деградационного фактора в территориальном аспекте, то есть для каждого населенного пункта. В свою очередь суммы баллов демонстрируют результирующие значения деградационных воздействий на окружающую среду на урбанизированные и пригородные территории. Данные балльной экологической диагностики антропотехногенной нагрузки в районе исследований отражены в таблице 2 .

Приведенные в этой таблице результаты дифференцируют значения антропотехногенных воздействий на объекты окружающей среды на городские и пригородные территории Прихоперья. Анализ позволил разделить урбанизированные районы на группы: с высокой антропотехногенной нагрузкой - Балашов (43,8 баллов); со средним уровнем нагрузки Борисоглебск $(35,2)$, Ртищево (33,9 баллов); с низким значением нагрузки - Поворино $(27,1)$ и Грибановский $(25,4$ балла); с крайне низкой нагрузкой - Романовка $(12,4)$, Аркадак $(18,4)$, Новохоперск $(15,7$ баллов). С учетом ежегодного роста числа автовладельцев и, соответственно, автомобильного транспорта, можно с большой долей вероятности прогнозировать усиление совокупного техногенного - физического и химико-токсического - пресса на экосистемы как в пределах урбанизированных территорий, в их окрестностях, так и в удаленных от них районах.
Обработанные и проанализированные данные реализованной программы экологического мониторинга обобщенно свидетельствуют о двух результирующих видах антропотехногенных воздействий на экосистемы и окружающую среду урбанизированных и пригородных территорий Прихоперья: 1) механических, 2) химических, и в том числе химико-токсических, загрязнителей (в составе выбросов и при последующих поступлениях вредных компонентов нефтепродуктов, соединений тяжелых металлов, газообразных и иного рода вредных веществ).

Первая группа негативных воздействий связана с прикатыванием почвенного и растительного покровов автотранспортом, притаптыванием пешеходами на городских и пригородных территориях. В результате нарушаются ярусы фитоценозов. Особенно отрицательные эффекты проявляются в уничтожении подстилки и травяного яруса, подроста древесных растений из местной флоры. Это ведет в итоге к встраиванию в растительные сообщества сорнорудеральных растений, часть из которых обладает аллергенным и мутагенным действием на человеческий организм. Существенную опасность представляет натурализация карантинных видов растений. Проблема биологических инвазий остается актуальной для Воронежской и Саратовской областей. Ослабление и уничтожение растений с полезными свойствами в биоценотическом, эколого-стабилизирующем, эколого-реабилитационном аспектах способствует распространению инвазионных видов в первую очередь в населенных пунктах, в их окрестностях и затем в удаленных от поселений территориях. Распространение инвазионных видов порождает другие проблемы в связи изменением состава, структуры сообществ, функциональных связей, энергетических балансов и биогеохимических круговоротов в биогеоценозах.

Также значимым отрицательным последствием с экологической точки зрения является обнажение почв и почвогрунтов, когда повышается уязвимость верхнего горизонта при физических, эрозионных и химических процессах. Обнажение почв и почвогрунтов опасно еще их излишним иссушением, что обусловлено, с одной стороны, умеренно континентальным климатом Прихоперья с преобладанием аридных процессов в летние сезоны (особенно в Саратовской области), с другой - образованием пыли. Вместе с пылевыми частицами, взвешивающимися и распространяющимися воздушными потоками и дождевыми водами при смывах, происходит распространение неспецифических для почв и растительности веществ, в том числе экотоксикантов и суперэкотоксикантов. В их составе также опасные и высокоопасные тяжелые металлы, другие различные неорганические и также органические вещества вредного действия на человека, животных, растения и другие биотические объекты. Это представляет, по сути, вторичный и последующие циклы эмиссии вредных веществ, в числе которых нефтепродукты и элементы группы тяжелых металлов, и загрязнения ими различных объектов в окружающей среде городских и пригородных территорий. Последующая деградация таких объектов ведет к потере ресурсных качеств эксплуатируемых экосистем и ландшафтов. 
Таблица 2 - Среднестатистические значения экологического состояния объектов окружающей среды Прихоперья

\begin{tabular}{|l|c|c|c|c|c|c|c|c|}
\hline Пасел. пункты & $\begin{array}{c}\text { Гриба- } \\
\text { новский }\end{array}$ & $\begin{array}{c}\text { Пово- } \\
\text { рино }\end{array}$ & $\begin{array}{c}\text { Ново- } \\
\text { хоперск }\end{array}$ & $\begin{array}{c}\text { Борисо- } \\
\text { глебск }\end{array}$ & $\begin{array}{c}\text { Арка- } \\
\text { дак }\end{array}$ & $\begin{array}{c}\text { Рти- } \\
\text { щево }\end{array}$ & $\begin{array}{c}\text { Рома- } \\
\text { новка }\end{array}$ & $\begin{array}{c}\text { Бала- } \\
\text { шов }\end{array}$ \\
\hline Уплотнение почв, баллы & 5,1 & 5,8 & 2,9 & 7,2 & 2,6 & 7,1 & 1,8 & 9,3 \\
\hline Плотность ДТС, баллы & 5,8 & 7,1 & 4,8 & 9,5 & 5,1 & 8,1 & 4,2 & 9,8 \\
\hline Захламленность почв, баллы & 8,2 & 7,2 & 4,4 & 2,5 & 4,2 & 8,4 & 4,1 & 5,1 \\
\hline Интенсивность пешеходов, баллы & 2,1 & 2,5 & 1,3 & 7,2 & 2,4 & 5,4 & 1,2 & 9,9 \\
\hline Интенсивность автотранспорта, баллы & 4,2 & 4,5 & 2,3 & 8,8 & 4,1 & 4,9 & 1,1 & 9,7 \\
\hline$\sum$ баллов & 25,4 & 27,1 & 15,7 & 35,2 & 18,4 & 33,9 & 12,4 & 43,8 \\
\hline
\end{tabular}

Анализируемые объекты - почвенный покров и растительность - состоят в группе первостепенных условий (совместно с поверхностными и подземными водоисточниками, продовольственными ресурсами, качеством социального и медицинского обслуживания) в жизнеобеспечении, регуляции и оптимизации биогеохимических круговоротов (в том числе почвы и растения являются главными депонирующими вредные вещества средами). То есть данные компоненты окружающей среды во многом создают и поддерживают на необходимом уровне условия экологического комфорта для жизни, отдыха и труда местных жителей. Они предоставляют жизнеобеспечивающие экосистемные услуги для населения. Таким образом, определенные эколого-диагностические значения и установленные уровни антропотехногенных нагрузок на окружающую среду в районе исследований отражают соответствующие лимиты экологической комфортности и благоустроенности поселений. Поэтому предложенную экологическую шкалу можно использовать в качестве комплексного индикатора оценки жизнеобеспечивающих услуг природно-хозяйственных и искусственных экосистем. Перечень параметров экологической оценки, безусловно, может быть расширен. Это полезно учитывать муниципалитетами при планировании и последующей реализации работ по благоустройству, защите и оздоровлению окружающей среды.

\section{Заключение}

В целом данные выполненного экомониторинга демонстрируют два ключевых тренда. Первый показывает преимущественный характер результатов антропотехногенных воздействий на урбанизированные территории. Он выражается в соответствующих среднеарифметических значениях уплотненности почв, плотности ДТС, захламленности. Второй экологический тренд связан с основными причинами антропотехногенного прессинга на рассматриваемые экосистемы, инициирующего условия нарушения и деградации почв, растительности и вызывающие ухудшение состояния воздушного бассейна на приземном уровне. Эти изменения в указанных компонентах экосистем обусловливают потерю ими ресурсных, средоформирующих, эколого-стабилизирующих и эколого-оптимизирующих свойств, что в итоге лимитирует целостность и общую функциональность озеленительных структур.

Дифференциация баллов антропотехногенной нагрузки предоставляет возможность для выработки природоохранных и эколого-реабилитационных программ, в том числе компенсационного, защитного, защитно-декоративного и декоративного озеленения, с обязательной детализацией мер, приоритетности, эффективности. В районе исследований эти программы должны сочетаться с установленными уровнями антропотехногенной нагрузки на объекты ок- ружающей среды и с местными градостроительными особенностями.

Грамотное использование средоформирующих, средорегулирующих, санитарно-гигиенических и комплексных утилитарных возможностей почвенного и растительного покровов в поселениях Прихоперья может позволить повысить их совокупную экологическую, ресурсную и художественно-эстетическую ценность. Важно, чтобы была выработана эффективная система управления защитой окружающей среды и природопользования с обязательным использованием экосистемного подхода к любой хозяйственной деятельности, связанной с городским и загородным природопользованием.

Предложенный балльный подход комплексного анализа важнейших эколого-диагностических признаков компонентов экосистем дает возможность объективно оценивать фактическое экологическое состояние и выявлять ситуации экологического неблагополучия как в антропогенно трансформированных территориях, так и в пределах сохранившихся природных комплексов за период эколого-мониторинговых исследований. Реализованный комплексный балльный экологический анализ являет собой контролирующий и в то же время корректирующий инструмент в экологическом проектировании и в последующей работе по конструировании новых экосистем, реконструкции и регуляции их. Он необходим также для гармоничного, эффективного управления различными сообществами, представляющими хозяйственную, декоративную, эколого-защитную и эколого-улучшающую значимость. Подобный подход в оценке экосистем представляется наиболее доступным, достоверным (в пределах статистически достоверных диапазонов средних арифметических данных мониторинга), объективным и высокоинформативным средством с научно-теоретической и прикладной точек зрения. Его можно внедрить в системы регионального и локального экологического мониторинга, ведомственного экологического контроля (в масштабах конкретных хозяйственных объектов и их объединений), в деятельность в рамках экологического проектирования.

Целесообразно использовать полученные и обработанные результаты экологического мониторинга, представленные в данной статье, в качестве ключевых критериев в экологической диагностике биокосных, косных и биотических компонентов экосистем района исследований. Ввиду того что эти объекты взаимосвязаны и взаимозависимы между собой в составе экосистем, комплексность эколого-мониторинговых исследований и последующих природоохранных и экологовосстановительных мероприятий будет благоприятствовать общему улучшению качества окружающей среды и повышению устойчивости сообществ и других составных частей местных ландшафтов. Все при- 
веденные наименования работ гармонично соотносятся с принципами рационального природопользования, обязательности эколого-охранной деятельности общества в ходе эксплуатации природных и природнохозяйственных систем и, следовательно, с идеей устойчивого развития различных территорий.

\section{Список литературы:}

1. Богучарсков В.Т., Князев Ю.П. Историко-географический анализ изучения ландшафтов бассейна Среднего и Нижнего Дона // Вестник Воронежского государственного университета. Серия: География. Геоэкология. 2012. № 2. С. 63-69.

2. Моников С.Н. История географических исследований Волго-Донского поречья во второй половине XVIII - начале XX в.: дис. ... канд. геогр. наук. M., 2007. $231 \mathrm{c}$.

3. Питьева К.Е., Смирнова А.Я., Смирнова А.А. Гидросфера северо-восточной территории Воронежской области // Вестник Воронежского государственного университета. Серия: География. Геоэкология. 2016. № 2. С. 101-115.

4. Фёдоров А.В., Макаров В.З. К методологии комплексного геоэкологического районирования региона на основе концептуальных моделей современного ландшафтоведения (на примере Саратовской области) // Известия Саратовского университета. Новая серия. Серия: Науки о Земле. 2019. Т. 19, № 2. С. 87-96.

5. Прихоперье / Ф.Н. Мильков, В.А. Прохоров, Н.И. Ахтырцева и др.; под ред. Ф.Н. Милькова. Воронеж: Изд-во Воронеж. ун-та, 1979. 163 с.

6. Ларионов М.В. Экобиологическая характеристика представителей сем. Formicidae в сосновых насаждениях Окско-Донской низменности: автореф. ... канд. биол. наук. Брянск, 2007. 22 с.

7. Учебно-краеведческий атлас Саратовской области / В.В. Аникин, Е.В. Акифьева, А.Н. Афанасьева и др. Саратов: Изд-во Сарат. ун-та, 2013. 144 с.

8. Эколого-географический атлас-книга Воронежской области / под ред. В.И. Федотова. Воронеж: Изд-во ВГУ, 2013. 514 с.

9. Буланый Ю.И. Ботанико-географическое районирование Саратовской области // Современные проблемы науки и образования. 2011. № 6. https://science-education.ru/ru/article/view?id=5242.

10. Камышев Н.С., Хмелев К.Ф. Растительный покров Воронежской области и его охрана: монография. Воронеж: Изд-во ВГУ, 1976. 184 с.
11. География Саратовской области / Н.Д. Добрина, Т.Д. Крысанова, В.К. Штырова и др. Саратов: Изд-во Сарат. ун-та, 1993. 220 с.

12. Жигулина Е.В. Трансформация ландшафтов бассейнов малых рек Воронежской области: дис. .. канд. геогр. наук. Воронеж, 2013. 193 с.

13. Larionov M.V., Soldatova V.V., Logacheva E.A., Larionov N.V., Ermolenko A.S. An ecological analysis of the composition and condition of woody plants in urban and suburban ecosystems of the Khopyor River Region // IOP Conf. Ser.: Earth and Environmental Science. 2020. Vol. 421, № 6. P. 1-9. DOI: 10.1088/17551315/421/6/062025.

14. Артемова С.Н., Леонова Н.А. Морфологическая структура ландшафтов Окско-Донской равнины в пределах Пензенской области // Известия Пензенского государственного педагогического университета им. В.Г. Белинского. 2011. № 25. С. 652-660.

15. Larionov M.V., Larionov N.V., Siraeva I.S, Gromova T.S., Soldatova V.V., Logacheva E.A. Ecological and aesthetic significance of an auto-trophic component of artificial ecosystems in ensuring of the environmental comfort and the public health protection // IOP Conf. Series: Earth and Environmental Science. 2020. Vol. 421, № 8. P. 1-5. DOI: 10.1088/1755-1315/421/8/082002.

16. Методические указания по оценке городских почв при разработке градостроительной и архитектурно-строительной документации. М.: Изд-во НИиПИИ экол. гор., 2003. 24 с.

17. Боговая И.О., Теодоронский В.С. Озеленение населенных мест: учеб. пособие для вузов. М.: Агропромиздат, 1990. $240 \mathrm{c.}$

18. ОСТ 56-100-95 Методы и единицы измерения рекреационных нагрузок на лесные природные комплексы. М.: Изд-во ВНИЦлесресурс, 1995. 14 с.

19. Методические рекомендации по регулированию пешеходного движения. М.: Изд-во ВНИИБД МВД СССР, 1977. 56 с.

20. Лобанов Е.М. Транспортная планировка городов: учебник для студ. вузов. М.: Транспорт, 1990. $240 \mathrm{c}$.

21. Пугачёв И.Н. Организация движения автомобильного транспорта в городах: учеб. пособие. Хабаровск: Изд-во ТОГУ, 2005. $196 \mathrm{c.}$

22. Зарубов А.И. Геоэкология человека. Мн.: Издво БГУ, 2007. 43 с.

\section{ANTHROPO-TECHNOGENIC LOAD ON THE ENVIRONMENT OF THE KHOPYOR RIVER REGION}

(C) 2020

Gromova Tatyana Sergeevna, postgraduate student of Botany and Ecology Department

Siraeva Irina Salavatovna, postgraduate student of Botany and Ecology Department

Ermolenko Anna Sergeevna, postgraduate student of Botany and Ecology Department Saratov State University (Saratov, Russian Federation)

Larionov Nikolai Viktorovich, candidate of biological sciences, director Secondary School № 2 of Kotelniki (Kotelniki, Moscow Region, Russian Federation)

Larionov Maxim Viktorovich, doctor of biological sciences, associate professor, professor of Biology and Ecology Department

Balashov Institute of Saratov State University (Balashov, Saratov Region, Russian Federation)

Abstract. The primary sources of anthropogenic and technogenic impacts on the environment of urban and suburban areas of the Voronezh and Saratov Regions which are part of the Khopyor River Region have been identified. Among the combined urbanized and man-made sources it is necessary to distinguish the activity of pedestrians and road transport. These conditions characterize the local background of the total anthropo-technological load in relation to the settlements of the research area. Its main manifestations include soil compaction, density of the road and path 
Громова Т.С., Сираева И.С., Ермоленко А.С., Ларионов Н.В., Ларионов М.В.

Определение антропотехногенной нагрузки на объекты окружающей среды Прихоперья

Общая биология

network and clutter. Arithmetic mean values of degradation impacts were analyzed for settlements in the subregion under consideration. A scale of point-based environmental assessment of the state of the environment is developed for differentiated localities in the Khopyor River Region. High anthropogenic and technogenic load is found in Balashov, middle - in Borisoglebsk, Rtishchevo, low - in Povorino and Gribanovsky, an extremely low load - in Romanovka, Arkadak and Novokhopersk. The obtained and analyzed values of anthropogenic and technogenic loads on the environment demonstrate the features of its state and the direction of its degradation, the levels of environmental comfort of urbanized areas for the population. The system of environmental quality management, urban and suburban environmental management in the Khopyor River Region should be reoriented to an ecosystem basis using the environmental assessment criteria and the environmental monitoring results presented and analyzed in this paper.

Keywords: environment; soil density; density of road and path network; soil clutter; pedestrian movement intensity; motor transport traffic; results of environmental monitoring; environmental assessment points; environmental trends.

$* * *$

УДК 502.1

DOI 10.24411/2309-4370-2020-11105

Статья поступила в редакцию 26.12.2019

\section{РЕЙТИНГОВЫЙ АНАЛИЗ СТРАН МЕЖГОСУДАРСТВЕННОГО ОБЪЕДИНЕНИЯ АТЭС ПО ИНДИКАТОРАМ УСТОЙЧИВОГО РАЗВИТИЯ}

(C) 2020

Зазнобина Наталья Ивановна, кандидат биологических наук, доцент кафедры экологии

Гелашвили Давид Бежанович, доктор биологических наук, профессор, заведующий кафедрой экологии Абдулхаков Тимур Михайлович, студент Института биологии и биомедицины

Голубков Вадим Андреевич, магистрант кафедры экологии

Национальный исследовательский Нижегородский государственный университет им. Н.И. Лобачевского

(2. Нижний Новгород, Российская Федерация)

Аннотация. В результате исследования проведен рейтинговый анализ социо-эколого-экономических систем (СЭЭС) стран межгосударственного объединения АТЭС по индикаторам устойчивого развития на основе обобщенной функции желательности. Для объективного анализа и корректного сопоставления разноразмерных индикаторов устойчивого развития, предложенных Комиссией ООН по устойчивому развитию и Всемирным банком, была использована процедура свертывания информации, предусматривающая использование обобщенной функции желательности (ОФЖ). Рассчитанные значения ОФЖ позволили провести комплексную оценку социо-эколого-экономического состояния стран межгосударственного объединения АТЭС. Составлен рейтинг исследуемых стран за 2007-2016 гг., который выглядит следующим образом: Новая Зеландия $>$ Перу $>$ Австралия $>$ Чили $>$ Канада $>$ Россия $>$ Малайзия $>$ Мексика $>$ Таиланд $>$ Филиппины $>$ Вьетнам $>$ Индонезия $>$ CША $>$ Республика Корея $>$ Япония $>$ Сингапур $>$ KHP. C помощью SWOT-анализа выявлены сильные и слабые стороны, вскрыты угрозы и перспективные возможности экологического, экономического и социо-демографического развития стран межгосударственного объединения АТЭС как единого регионального образования. Рейтинг стран, построенный на основе комплекса индексов устойчивого развития с применением обобщенной функции желательности, корректно подтверждается и аналитически объясняется SWOT-анализом, являющимся методом стратегического планирования развития регионов.

Ключевые слова: Азиатско-Тихоокеанское экономическое сотрудничество; индикаторы устойчивого развития; индекс развития человеческого потенциала; показатели мирового управления; экологический след; биоемкость; выбросы двуокиси углерода; плотность населения; обобщенная функция желательности; социоэколого-экономическое состояние; рейтинговый анализ; SWOT-анализ.

В настоящее время процессы глобализации, в том числе интеграция и регионализация, охватили практически все страны мира. Азиатско-Тихоокеанский регион не является исключением, что проявилось в создании организации АТЭС, являющейся самым большим региональным объединением в мире, показатели которого говорят сами за себя: на долю участников форума приходится 40\% населения Земли, $60 \%$ мирового ВВП и 50\% мировой торговли [1]. Российская Федерация является активным участником АТЭС с 1998 года, инициативно участвует в процессе его обновления и реформирования, имеет весомый голос в дискуссиях.

Другая глобальная проблема - устойчивое развитие территории любого масштаба. Понимание состояния социально-экологической системы важно для социально-экономического развития любого государства, а также для управления природными ресур- сами [2]. Как известно, цели в области устойчивого развития, изложенные в «Повестке дня в области устойчивого развития на период до 2030 года», направлены на принятие усилий по наращиванию экономического роста, решению социальных вопросов в области образования, здравоохранения, трудоустройства, а также на борьбу с изменением климата и защите окружающей среды [3]. В настоящее время в мире ведется много исследований по разработке индикаторов устойчивого развития. Однако трудно идентифицировать именно те индикаторы, которые позволяют адекватно оценить степень устойчивости стран в международном масштабе, поскольку существуют объективные трудности статистической обеспеченности.

На данный момент существуют рейтинги стран, составленные международными организациями по отдельным индикаторам и индексам устойчивого 